\title{
Dynamics of Environmental lonizing Radiation between May to September 2016 in the Region of São José dos Campos, SP, Brazil
}

\author{
Inacio M. Martin, Marcelo P. Gomes, Mauro A. Alves, Alessandro de Abreu, Franklin A. Silva, Rodrigo R. F. \\ Carvalho, João P. Correa and Bogos N. Sismanoglu \\ Physics Department, Technological Institute of Aeronautics-ITA, São José dos Campos, SP 12228-900, Brazil
}

\begin{abstract}
Measurements of gamma radiation (200 keV to $10 \mathrm{MeV}$ ) were performed between May 25 to September 302016 at ITA (Technological Institute of Aeronautics) in São José dos Campos, SP, Brazil. Detector and associated electronics were previously calibrated in the laboratory of ITA using radioactive sources Cs-137, Po-210 and Sr-90. These sources provide gamma-ray energies in $0.662 \mathrm{keV}$ alpha particles of $5.4 \mathrm{MeV}$ and $0.90 \mathrm{keV}$ electrons, respectively. Detector is a scintillator Sodium Iodide activated with Thallium $[\mathrm{NaI}(\mathrm{Tl})]$ associated to a photomultiplier and electronic devices which gather, store, distribute and structure data so users can analyze them. During the period of May-September, the experimental set was installed in an open room on a tower 25 meters above the ground. Measurements indicated variations of ionizing radiation in function of dry weather, rain, cold fronts passes and presence of fog in the area; the sample time interval was minute by minute. This study discusses the analysis and the dynamics of how to measure meteorological parameters using an ionizing radiation system.
\end{abstract}

Key words: Ionizing radiation, environmental study, gamma radiation measurements.

\section{Introduction}

In the (soil/air) interface of the Earth's surface, ionizing radiation is mainly comprised of radon gas, the telluric radiation from the ground and the primary and secondary cosmic ray radiation. However, it is difficult to separate over time the intensity of ionizing radiation emanating from each component as the energies overlap. The telluric radiation is constituted by ${ }^{238} \mathrm{U},{ }^{235} \mathrm{U},{ }^{40} \mathrm{~K},{ }^{232} \mathrm{Th}$ chains and it is constant for each region [1]. Radon gas Ra-220 and Rn-222 is measured by isotopes ${ }^{214} \mathrm{~Pb},{ }^{214} \mathrm{Po}$ and ${ }^{214} \mathrm{Bi}$ originating from the uranium decay of the earth's crust [2]. The primary cosmic radiation mainly consists of galactic and extragalactic protons from the sun with very high energy which interact with the Earth's atmosphere producing the EAS (Extensive Air Showers) [3]. The efficiency of this interaction is maximal when it occurs

Corresponding author: Inácio M. Martin, Ph.D., main research fields: space physics and geophysics. at altitudes between $15 \mathrm{~km}$ and $17 \mathrm{~km}$ in the tropics forming secondary cosmic rays with muonics, mesonics and neutronics components that propagate to the Earth's surface in the region [4]. These radiations cause health problems for the crew and passengers of civil aviation and are present at the beginning of the stratosphere called maximum Pfotzer.

However, this component contributes less to radiation concentration on the Earth's surface. Another possible existing ionizing radiation source in the lower atmosphere of the Earth is produced by electrical discharges between clouds-earth-ground and clouds-clouds. $\mathrm{X}$-rays, gamma rays, neutrons and beta particles are formed all the way of the lightning cone [5]. Other ionizing radiation sources are those produced in medical and dental clinics and hospitals, but these radiations are mostly controlled in small areas.

\section{Material and Methods}

To monitor the gamma radiation in range between 
$200 \mathrm{keV}$ and $10.0 \mathrm{MeV}$, a portable system composed of a scintillator Sodium Iodide activated with Thallium $[\mathrm{NaI}(\mathrm{Tl})]$ has been used. This crystal (3" $\times 3$ ") inches wrapped in a thin cylinder of aluminum coupled with a Photomultiplier (PM) with source power circuit in $1,500 \mathrm{VDC}$ and with data acquisition system provided by the company (Aware Electronics-Inc., USA) [6]. Detector and associated electronics were previously calibrated in ITA laboratory using radioactive sources Cs-137, Sr-90 and Po-210 in terms of energy from emitted photons and particles. The rainfall intensity in $\mathrm{mm}$ at each sampling minute was observed through a system (bascule/bucket) rain gauge and data logger acquisition developed in ITA according to the international recommendations [7]. The data acquisition in terms of ionizing radiation and intensity of rainfall was performed using 1-minute time interval between each measurement. This detail contributes to verify possible correlations between variation of rain intensity, and local ionizing radiation. The set of devices were installed at a room 25 meters high from the ground where it was monitored gamma rays and all associated electronics [8]. The rain detector is placed on the outside on top of the room with electrical and electronic connection with cables connected in computers and data logger inside room. Fig. 1 shows the structure of the tower on the outside and inside, closed with controlled room temperature of 20 degrees Celsius.

\section{Results and Discussion}

The measures of environmental ionizing radiation were made 25 meters high inside the room as shown in Fig. 1. The gamma-rays measures ranging from 0.020 to $10.0 \mathrm{MeV}$ in that period are shown in Fig. 2.

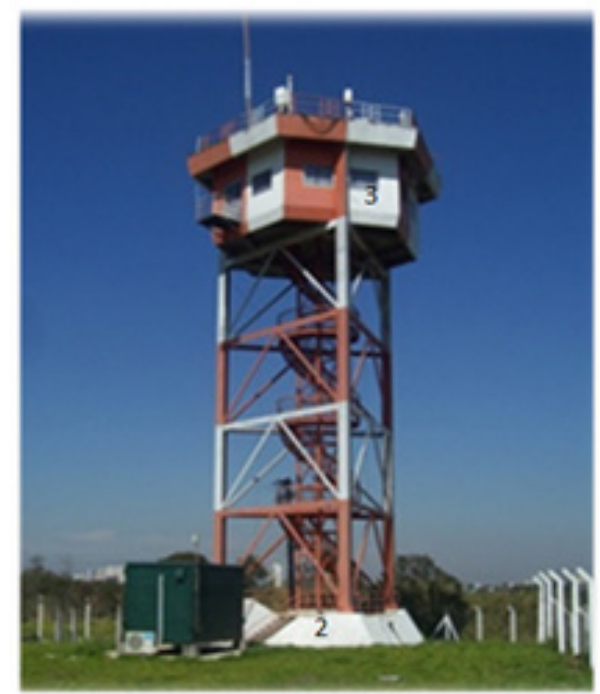

Fig. 1 Outside view of room on the top of tower with the detectors.

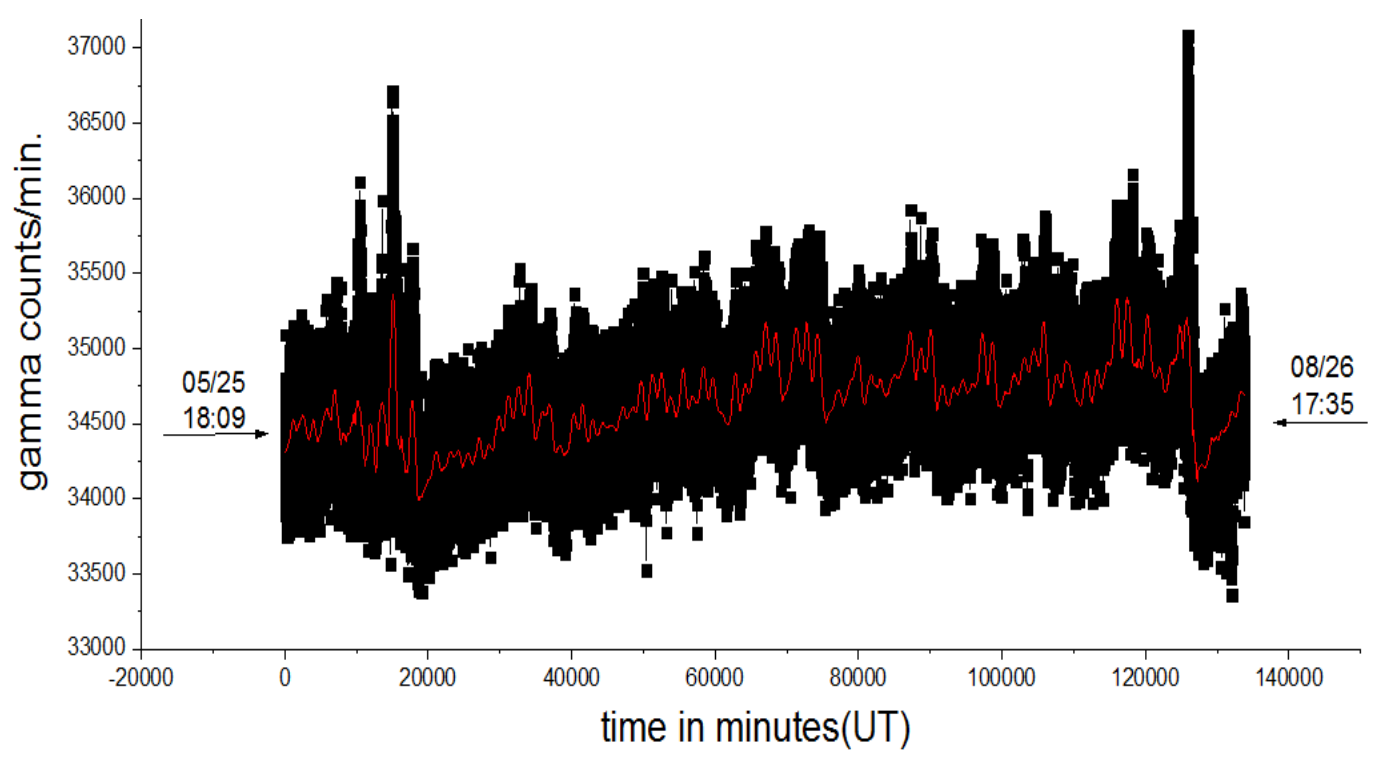

Fig. 2 Measurements of gamma radiation between $05 / 25$ to $08 / 26$ of 2016 . 
Checking the measurements shown in Fig. 2 with a zoom among minutes 10,000-19,000 as shown in Fig. 3, it is noted that several variations of intensity on gamma radiation indicats the presence of rain at the place and time observed. In the meantime, the intensity of rain that reached net $86.0 \mathrm{~mm}$ was measured, value up average for the period in the region.

Observing the radiation measurements described in Fig. 2 shows between 125,000 to 127,000 minutes the presence of rain as pointed out (zoom) in Fig. 4. In this interval time, it rained net $38 \mathrm{~mm}$ from 26 August to 26 September. In 2016, there was very few presence of rain in the region. The curve of environmental ionizing radiation measurements in this period is plotted in Fig. 5. It is noted that during 15,000 and 34,000 minutes there had been rain with $5 \mathrm{~mm}$ and $6.5 \mathrm{~mm}$ of intensities respectively.

Fig. 5 shows the measurements of gamma rays in the same location, but from 08/26 August to 09/26 September 2016.

The spectrum in time of rainy occurred during the radiation measurements (see Fig. 3) also was measured near the gamma ray detector as shown in Fig. 6. Between the 7 th of June and the end of August, there

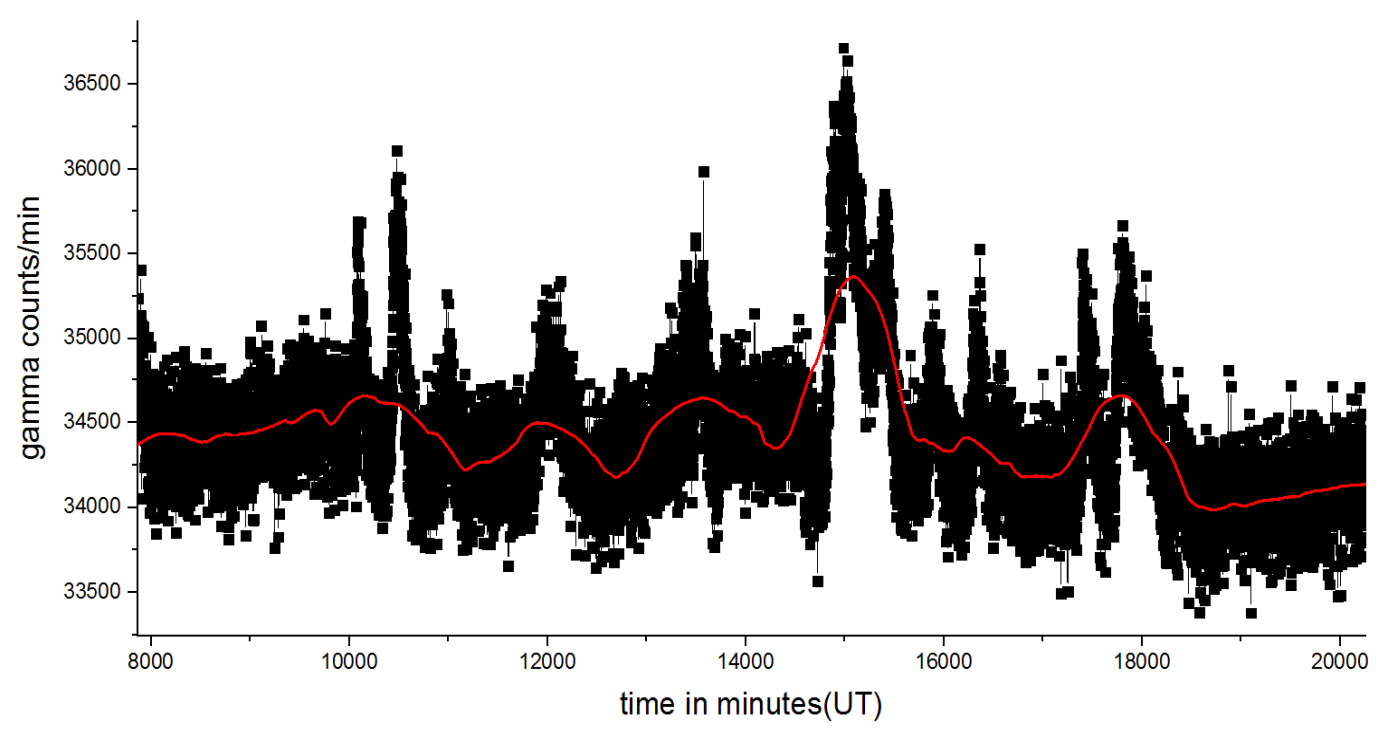

Fig. 3 Variation of gamma radiation indicating the net variation value of rain intensity at the region $(109 \mathrm{~mm})$.

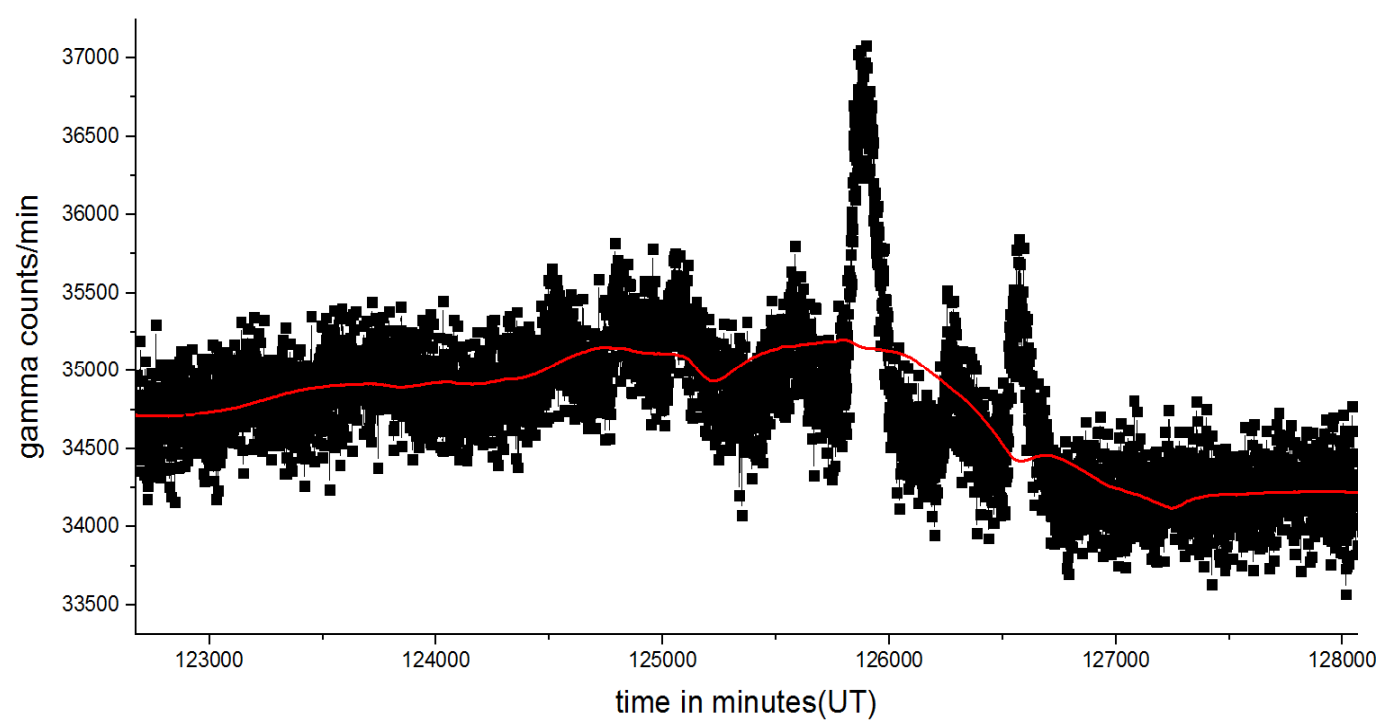

Fig. 4 Variation of gamma radiation indicating the correlation with rain intensity. 


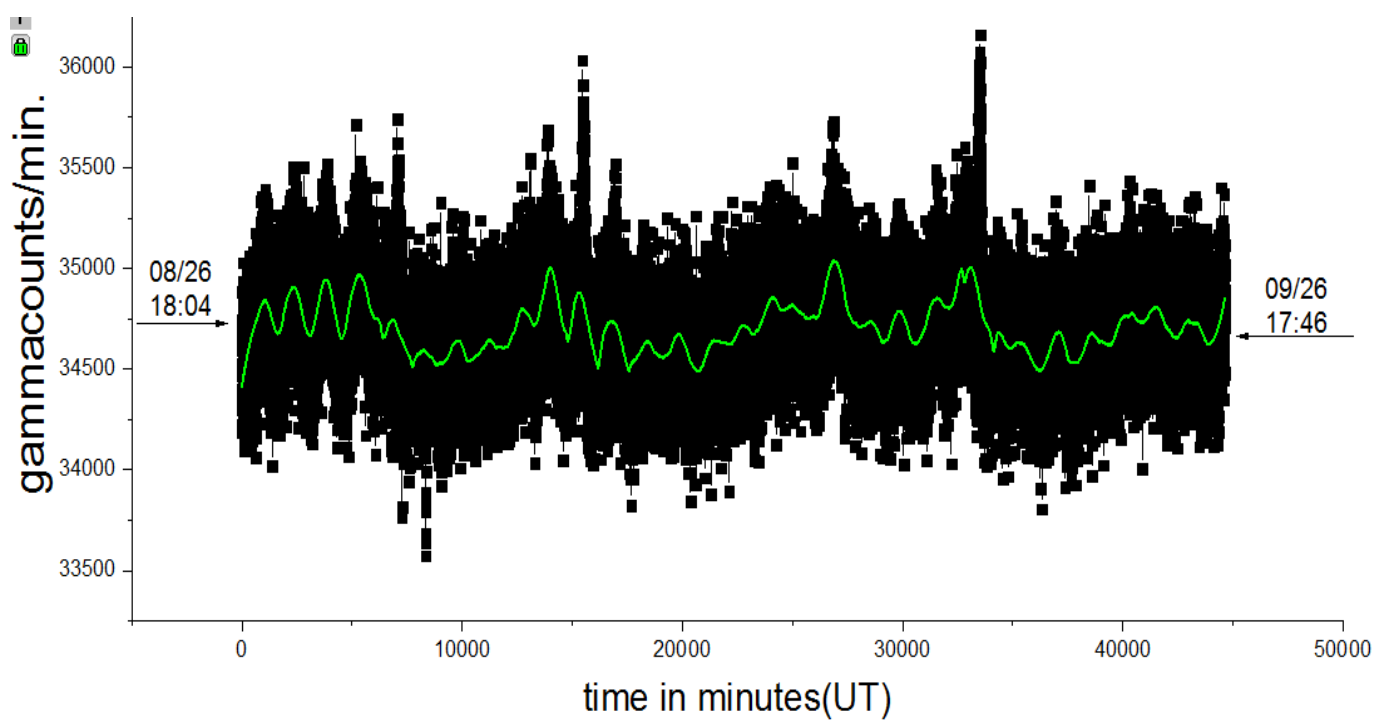

Fig. 5 Radiation gamma (0.02-10.0) MeV measurements every minute between 08/26 to 09/26 2016.

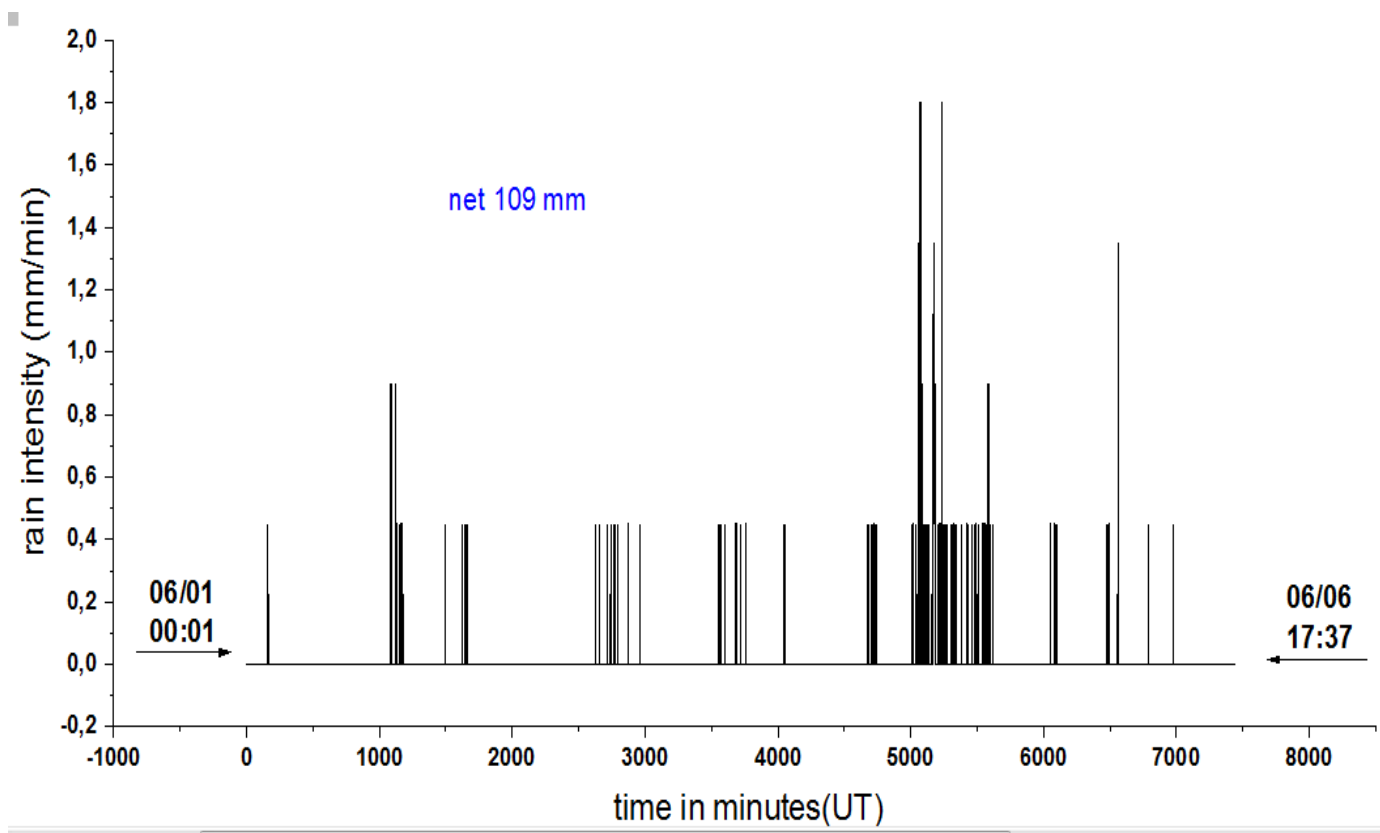

Fig. 6 Distribution spectrum in time of heavy rainfall occurred between June 06/01 to 06/06 June 2016 in the region of São José dos Campos, SP, Brazil.

was no rain in the recorded area. But on the 24th and 25 th of August, it rained with a total of $38 \mathrm{~mm}$. Fig. 7 shows the spectrum in time of rainfall as a function of time these days. Fig. 8 shows the distribution of rainfall in time between the 18th and 19th of September 2016. This period was the most intense of rain coming from Jun. 01 to Jun. 06 of 2016; 109 mm was recorded (Fig. 6).

That was the most significant rain for the period of $08 / 26$ to $09 / 262016$. Two other small showers, smaller than $2.5 \mathrm{~mm}$ intensities values, occurred in this period, being the net value $(16 \mathrm{~mm})$ far below the historical average of the region for the months of August-September (40 mm).

\section{Conclusion}

It was verified through measuring the dynamics of ionizing radiation variation in the environment from May to September 2016 in the São Jose Campos, SP, in 


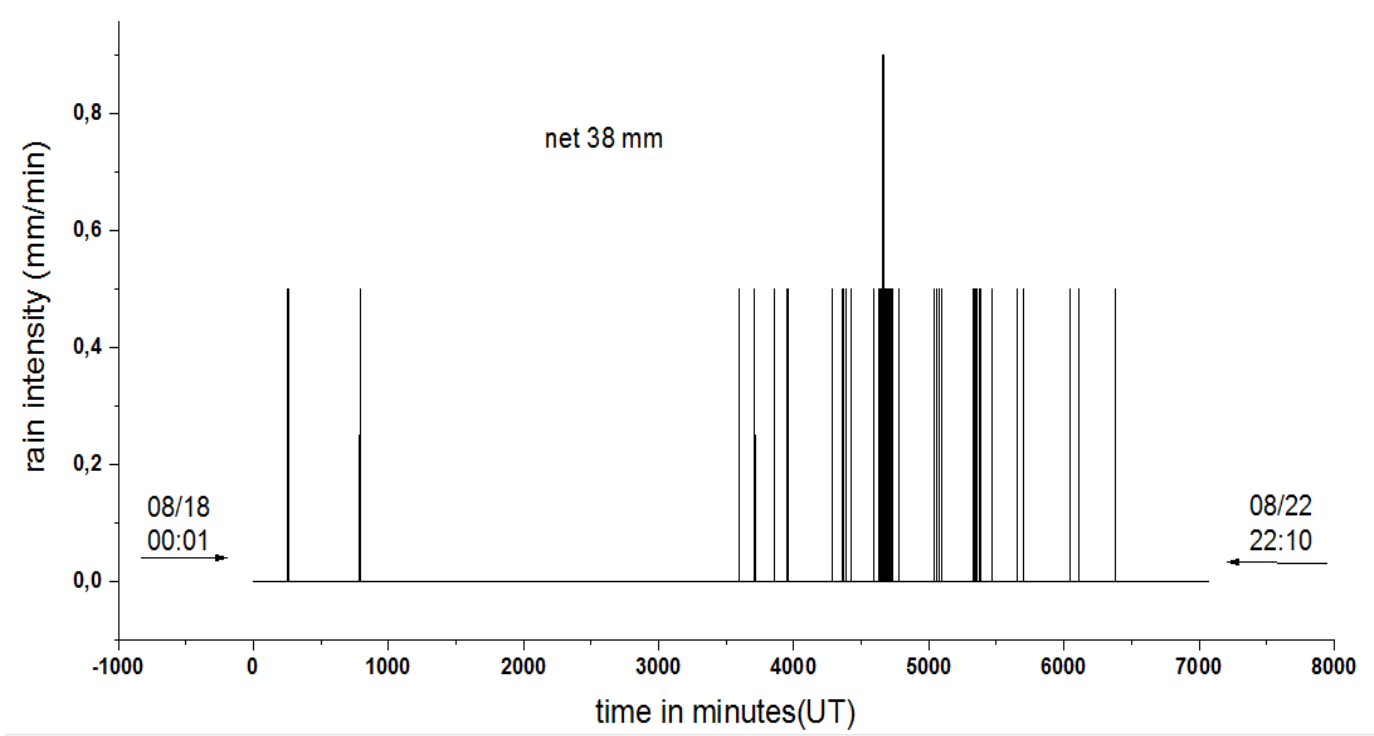

Fig. 7 Moderate rain distribution spectrum occurring between 18 to 22 August 2016 on the campus of the ITA, in the region of São José dos Campos, SP, Brazil.

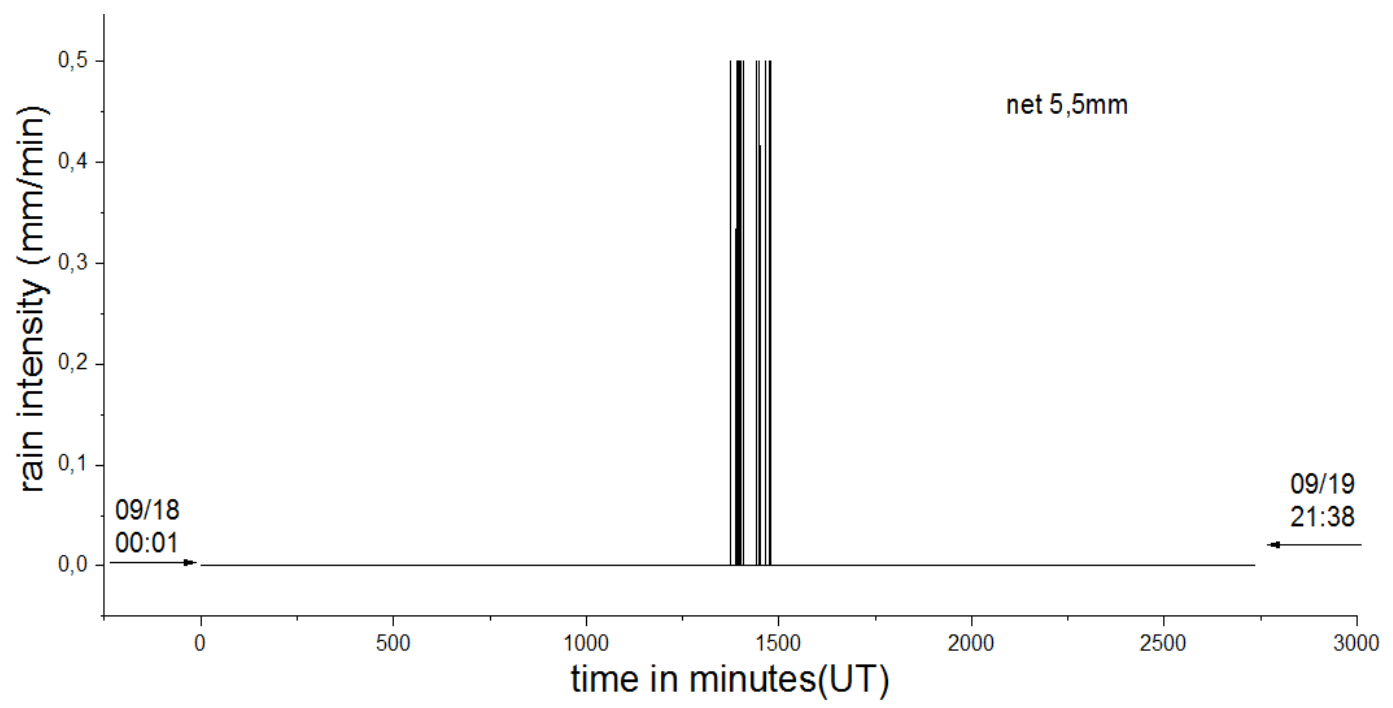

Fig. 8 Day of rain in 18/09 occurred between 20:00 and 21:00 (LT) with a total of $5.5 \mathrm{~mm}$.

Brazil region. May and June are very dry in the region but there was a very significant change in 2016 with interval of heavy rainfall $(109 \mathrm{~mm})$ and others moderate rains in August $(38 \mathrm{~mm})$. The month of July was completely dry without any rain this period. In September, the intensity was much lower $(16 \mathrm{~mm})$ than historical average of the region that is $40 \mathrm{~mm}$. This dynamic variation in the intensity of rainfall in the region was observed just measuring the intensity of ionizing radiation per minute on site. This is only possible in tropical and equatorial regions due to higher solar incidence in the crust land and the releasing of tracer radon gas that exalated from the earth's surface, the gas radon Ra-220 and Rn-222. These components emit ionizing particles and photons whose measures indicate presence of rain on the site.

\section{Acknowledgment}

Thanks CNPq (National Counsel of Technological and Scientific Development) and CAPES (Coordination for the Improvement of Higher Education Personnel) by the fellowships grants support to the group's researchers. The ITA Division of Fundamental Sciences for supporting this research. 


\section{References}

[1] Bui, Van, N. A., Martin, I. M., and Júnior, A. T. 1988. "Measurements of Natural Radioactivity at Different Atmospheric Depths." Geophysics Magazine 28: 262-266.

[2] Fujinami, N. 2009. "Study of Radon Progeny Distribution and Radiation Dose Rate in the Atmosphere." Japan Journal Health Physics 44 (1): 88-94.

[3] Grieder, P. K. F. 2010. Extensive Air Showers, Book Springer: Verlag Berlin Heidelberg.

[4] Jayanthi, U. B., Gusev, A. A., Neri, J. A. C. F., Villela, T., Júnior, O. P., Pugacheva, G. I., et al. 2005. "Ground Gamma Radiation Associated with Lightning and Rain Precipitation." In Proceedings of the 29th International Cosmic Ray Conference, 177-80.

[5] Babich, L. P., Bochkov, E. I., Kutsykand, I. M., and Rassoul, H. K. 2014. "Analysis of Fundamental Interactions Capable of Producing Neutrons in Thunderstorms." Physical Review D 89, 093010 DOI:
10.1103/PhysRevD.89.093010.

[6] Martin, I. M., Gomes, M. P., Sismanoglu, B. N., Santos, T. A. D., and Corrêa, J. P. 2015. "Monitoring of Ionizing Radiation Using Geiger Instrument, in São José Dos Campos, SP, Brazil." Journal of Environmental Science and Engineering DOI: 10.17265/2162-5298/2015.06.002 A4, pg, 282-285.

[7] Gomes, M. P., Martin, I. M., Sismanoglu, B. N., Alves, M. A., Ferro, M. A., and Abreu, A. 2016. "X and Gamma Ray Monitoring up to $10.0 \mathrm{MeV}$ in the Tower (TOFA/ACA/IAE) during January to September 2015 in São Jose dos Campos, SP, Brazil." Presented in VI Brazilian Symposium of Space Geophysics and Aeronomy (SBGEA 2016) held in Jataí, State of Goias, in Brazil.

[8] Martin, I. M., Thiago, A. T., da Silva, F. A., Gomes, M. P., and Sismanoglu, B. N. 2015. "Monitoring of Ionizing Radiation and Rain Intensity during May to October 2015 in São José dos Campos, Brazil." Journal of Environmental Science and Engineering B 2: 941-944. 